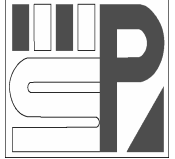

Science Press

Journal of Arid Land

2012, 4(4): 378-389

doi: 10.3724/SP.J.1227.2012.00378

jal.xjegi.com; www.chinasciencejournal.com

\title{
Using the concept of ecological groundwater level to evaluate shallow groundwater resources in hyperarid desert regions
}

\author{
Qi FENG ${ }^{1,2,3 *}$, JiaZhong PENG ${ }^{1,3}$, JianGuo $\mathrm{LI}^{1,3}$, HaiYang $\mathrm{XI}^{1,3}$, JianHua $\mathrm{SI}^{1,3}$ \\ ${ }^{1}$ Alashan Desert Eco-hydrology Experimental Research Station, Cold and Arid Regions Environmental and Engineering Research \\ Institute, Chinese Academy of Sciences, Lanzhou 730000, China; \\ ${ }^{2}$ Department of Geography, Shaanxi Normal University, Xi'an 710062, China; \\ ${ }^{3}$ Gansu Hydrology and Water Resources Engineering Center, Lanzhou 730000, China
}

\begin{abstract}
This paper, based on the analysis and calculation of the groundwater resources in an arid region from 1980 to 2001, put forward the concept of ecological groundwater level threshold for either salinity control or the determination of ecological warning. The surveys suggest that soil moisture and soil salinity are the most important environmental factors in determining the distribution and changes in vegetation. The groundwater level threshold of ecological warning can be determined by using a network of groundwater depth observation sites that monitor the environmental moisture gradient as reflected by plant physiological characteristics. According to long-term field observations within the Ejin oases, the groundwater level threshold for salinity control varied between $0.5 \mathrm{~m}$ and $1.5 \mathrm{~m}$, and the ecological warning threshold varied between $3.5 \mathrm{~m}$ and $4.0 \mathrm{~m}$. The quantity of groundwater resources (renewable water resources, ecological water resources, and exploitable water resources) in arid areas can be calculated from regional groundwater level information, without localized hydrogeological data. The concept of groundwater level threshold of ecological warning was established according to water development and water resources supply, and available groundwater resources were calculated. The concept not only enriches and broadens the content of groundwater studies, but also helps in predicting the prospects for water resources development.
\end{abstract}

Keywords: evaluation; water resources; Ejin oasis; ecological groundwater level; groundwater level threshold of ecological warning

Oases are the most fundamental ecosystem in arid desert regions (Wang et al., 2011). The ecological carrying capacity of water resources in desert oases is quite limited and ecosystems are very fragile. Accordingly, it is important to address the issue of regional ecological balance when exploiting water resources in arid regions (Gao and Li, 1991; Enrico et al., 2002; Cao and Feng, 2012). To protect headwater areas and rationally exploit water resources in a more efficient manner, the water-regulating functions of alpine ice-snow, forests, grasslands, gobi and deserts must be investigated (Cheng and Qu, 1992; Zhu and Wang, 1993; Dong et al., 1995; Umar et al., 2001).

Hydrologists have been paying little attention to ecological issues in the exploitation of water resources (Asbjornsen et al., 2007; Xi et al., 2010; Zhu et al., 2010). People generally believe that the dynamic water resources in arid regions can be equated to exploitable water resources and that groundwater serves as a rapid readjustment factor (Charney et al., 1975). Such ideas have led to the excessive exploitation of groundwater in many regions. Ecological views and theories should, therefore, be employed in investigating water resources and in developing environmental assessments of water resources.

Desert riparian forests serve as a natural screen to

Received 2012-02-23; accepted 2012-06-01

*Corresponding author: Qi FENG (E-mail: qifeng@1zb.ac.cn) 
protect the ecosystem in arid desert environments, such as in the arid zones of Northwest China, where oases on river sides represent some of the richest desert ecosystems. These special ecosystems, populated with Populus euphratica Oliv. (poplar) and Tamarix ramosissima Ledeb. (tamarisk), are internally controlled and interact with surrounding deserts (Jin et al., 2008).

Over the past 40 years, the agroecosystems in the middle and lower reaches of the Heihe River have been rapidly deteriorating due to anthropogenic factors including large-scale exploitation of surface and ground water resources. Overexploitation of water resources in the midstream of the river has led to the lowering of water table depths (WTD), drying up of lakes, wilting of plants, degradation of oases and exacerbation of dust storms.

Between 1960 and 2001, in the Ejin region, the area of Populus euphratica Oliv. forest decreased from $2.94 \times 10^{4} \mathrm{~km}^{2}$ to $2.06 \times 10^{4} \mathrm{~km}^{2}$; the area of Tamarix ramosissima Ledeb. forest from $1,500 \mathrm{~km}^{2}$ to $837 \mathrm{~km}^{2}$; and the area of Haloxylon ammodendron (C. A. Meyer) Bunge from $2,550 \mathrm{~km}^{2}$ to $1,852 \mathrm{~km}^{2}$, and is continuing to decrease at a rate of $27 \mathrm{~km}^{2} / \mathrm{a}$ (Liu and Zhang, 2002; Feng et al., 2004).

The number of woodland's plant species has decreased from about two hundreds to a few dozens. Desert plant species such as Calligonum mongolicum Turcz., Artemisia desertorum Spreng. and Nitraria tangutorum Bobrov have died out over large areas and vegetation cover decreased by $30 \%-80 \%$ from 1960 to 2001. Biomass of natural grasslands decreased accordingly during the same period (Shu et al., 1998). Degradation of the vegetation has exacerbated land desertification in the region. Sand and dust materials taken up and transported by wind seriously pollute the environment. During the period of 1989-2000, 55 dust storm events occurred in the downstream of the Heihe River, averaging 5 times per year, which is four times than before 1980 (Wang et al., 2003).

In recent years, the river basin has faced increasingly serious ecological challenges, including the demise of large tracts of vegetation, land desertification and salinization, as well as a high frequency of sand storms (Wu et al. 2002; Feng et al. 2004). Because of the unique geographical location and arid features in the Heihe River Basin, the relationship between groundwater level and vegetation growth has become an issue of widespread and high-priority concern.

Over the past few decades, scientists have carried out many researches on the assessment and utilization of water resources in the Heihe River Basin to understand the relationship between water and environment and improve water management practices (Feng, 1999). Chen et al. (2006) studied the recharge and residence time of groundwater in the Heihe River Basin by using environmental isotopes. Wu et al. (2004) analyzed the exchange between groundwater and river water by using the ${ }^{222} \mathrm{Rn}$ isotope in the middle of the Heihe River Basin. The study of Chen et al. (2006) revealed that the deep confined groundwater has an age between 0 and 10,000 years, but the shallow unconfined groundwater was recently recharged by the Heihe River and irrigation return flow from agricultural areas. However, previous work has put little emphasis on comprehensive approaches to understanding the relationship between groundwater level and ecological systems as well as the interaction between soil water, groundwater and water in ecosystems.

Based on long-term field observations of soil water and groundwater in the lower reaches of the Heihe River by using automatic instruments, the current study tries to elucidate (i) variations in soil water and groundwater, (ii) the main controls on the vegetation growth imposed by hydrological conditions, and (iii) the development of a conceptual model linking soil water, evaporation, and groundwater in different growing periods of vegetation.

\section{Materials and methods}

\subsection{Study area}

The research was conducted at the Alashan Desert Eco-hydrology Experimental Research Station (abbreviated as Alashan Station) (883.54 m asl) located in the Ejin oasis in the lower reaches of the Heihe River, an area which covers more than $6 \times 10^{5} \mathrm{~km}^{2}$ in northwestern China (Fig. 1). The oasis in the central part of the Heihe River Basin has a slope gradient of $1 / 100-1 / 1,200$, with its topography sloping northeastward (Fig. 1; Feng et al., 2002). The region's climate is extremely dry with a mean annual precipitation of 


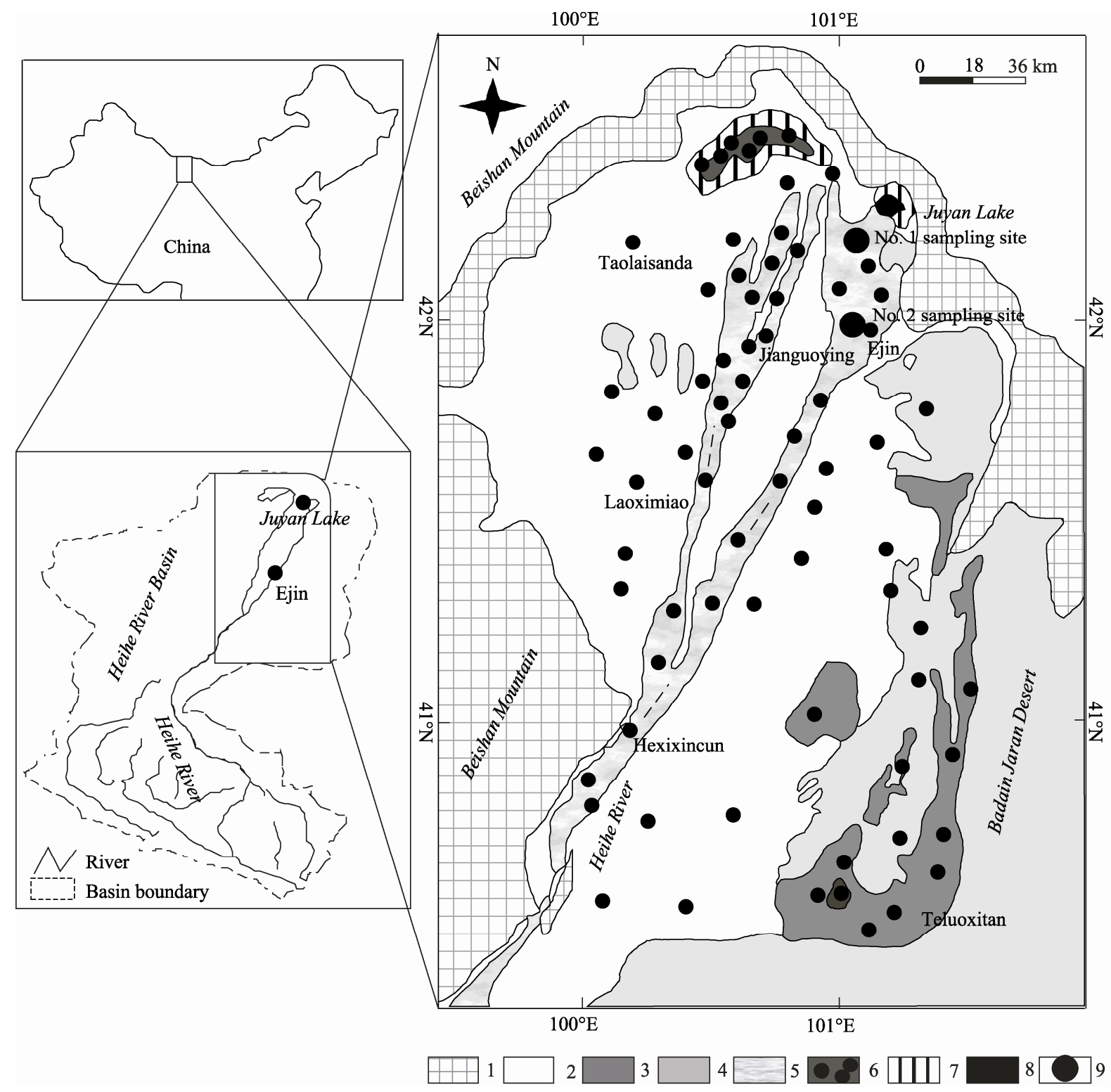

Fig.1 The location of Ejin oasis and sampling sites within the Heihe River Basin and China. 1, Bedrock; 2, Gobi; 3, Wetland; 4, River course; 5, Desert; 6, Ancient lake; 7, Swamp; 8, Lake; 9, Sampling points.

$36.6 \mathrm{~mm}$, and less than $10 \mathrm{~mm}$ in some places. The mean annual evaporation is $3,505.7 \mathrm{~mm}$, with a maximum value of $4,384.4 \mathrm{~mm}$. Heat energy is abundant, with an annual mean air temperature of $8.2^{\circ} \mathrm{C}$. The existence of the oasis relies entirely on water from the upper and middle reaches of the Heihe River (Feng and Liu, 2003).

Plant species in the study area are sparsely distributed. According to field investigations, there are 268 species, 151 genera and 49 families of plants in the area. Of the 49 families, some contain more than 30 species, including Compositae (81 species), Chenopo- diaceae (47 species) and Gramineae (33 species); other families include Leguminosae (15 species), Polygonaceae (11 species), Cyperaceae (11 species) and Tamaricaceae (10 species). The above seven families contain 208 species, accounting for $72 \%$ of the total species number; they are the dominant plant species in the region (Si et al., 2008). Some mesophytic and hydrophilous trees, shrubs and herbs occur along the banks of the Ejin River and in the lacustrine plain, the main species being Populus euphratica, Elaeagnus angustifolia L., Tamarix spp., Phragmites communis Trin., Achnatherum splendens (Trin.) Nevski, Sophora 
alopecuroides L., Glycyrrhiza uralensis Fisch., Carex spp., etc. Species surrounding the oasis include various shrubs and herbs, such as Nitraria tangutorum, Artemisia spp., and Agriophyllum arenarium M. Bieb. Some sparse xeric species occur in the low-mountain and hilly regions and gobi plains, including Reaumura soongorica (Pall.) Maxim., Nitraria sphaerocarpa Maxim., Ephedra przewalskii Stapf, Zygophyllum xanthoxylon (Bunge) Maxim., Sympegma regelii Bunge, Anabasis brevifolia C. A. Mey. and Calligonum spp., etc.

The soil parent materials of sandy gobi in the Ejin delta are river alluvial-diluvia deposits, and long periods of wind erosion have greatly decreased fine soil particle content (Feng et al., 2009).

\subsection{Methods}

Soil water content measurements were taken weekly from the surface to a depth of $1.0 \mathrm{~m}$, using both neutron moisture probe (MODEL 4300, Troxler Electronic Laboratories, Inc., Research Triangle Park, North Carolina, USA) and oven drying methods. In the top 0.2-m soil layer, a surface neutron moisture probe was used to measure the average moisture. The probe was calibrated at the time of tube installation using gravimetric soil water and bulk density measurements (Holmes, 1956).

The soil physical characteristics were determined from core samples using ceramic tension tables and a pressure plate apparatus following the procedure of the US Soil Conservation Service (1967). Bulk density was determined using samples of a given volume processed in a steel cylinder. Soil property measurements were taken at eight sites in the sampling period of 2005-2008. The analysis methods were from Briggs and Shantz (1921), Bresler et al. (1969), and Hillel $(1974,1982)$.

The particle size distribution of soil samples was determined by sieving the aqueous suspension after dispersion by treatment with hydrogen peroxide to remove organic matter, hydrochloric acid to remove carbonate, and mechanical agitation in dilute sodium hexametaphosphate solution (Bouyoucos, 1951; Brewer, 1964).

For bulk density and organic matter content analyses, soils were sampled at different depths of the 1-m topsoil using a steel cylinder $\left(100 \mathrm{~cm}^{3}\right)$, and samples were brought to the laboratory, dried for 1 day at $105^{\circ} \mathrm{C}$ and analyzed soon afterward. Organic matter content was determined by the loss-on-ignition methods $\left(4 \mathrm{~h}\right.$ at $\left.650^{\circ} \mathrm{C}\right)$. The average organic matter content in every $0.1-\mathrm{m}$ soil layer was calculated from three replicate samples drawn from that layer.

The ${ }^{13} \mathrm{C}$ and ${ }^{18} \mathrm{O}$ stable isotope composition of $\mathrm{CaCO}_{3}$ (aragonite plus calcite) was measured for the $<62.5$ $\mu \mathrm{m}$ fraction of 22 samples using a VG PRISM mass spectrometer and standard preparation methods (Drimmine et al., 1992). Selective acid extraction provided data for $\mathrm{CaCO}_{3}$ with minimal dolomite interference (Al Aasm, 1990). Replicate analysis results were within $\pm 0.4 \%$, as outlined in Tarutani et al. (1969), Van Stempvoort et al. (1994), and Romanek et al. (1996).

Soil electrical conductivity was determined using electromagnetic induction (Rhoades and Corwin, 1980; Corwin and Rhoades, 1982; Dalton et al., 1984). Details of measurement methods and calibrations for each individual soil sample were obtained from Rhoades (1976, 1978, 1980 and 1984). Chinese Hydrological Yearbooks, compiled for provinces including Qinghai, Gansu, and Inner Mongolia, present detailed hydrological information dating back to the 1960s. Data from three gauging stations in the region, covering more than 40 years, were available. Groundwater information was obtained from the Survey Reports of the Second Geology Investigation Team (1975, 1990, 1995, and 2008).

Precipitation, evaporation and other meteorological data for the region mainly came from weather stations, with $99 \%$ of the records being complete from 1960 to 2008. A relatively stable network of stations and consistency in the operational procedure since 1960 ensure the quality of surface observations. Other data such as vegetation cover and desertified land area were drawn from various references.

\section{Results and discussion}

\subsection{Relationship between groundwater table depth and ecological balance}

Groundwater constitutes the main part of water resources and plays an important role in water supply and eco-environment management in the arid Ejin. The main eco-environmental problems are soil salinization and vegetation degradation. The groundwater's eco-environmental indices vary with regions, and the threshold values of the indices change according to the 
climatic and soil conditions. In an artificial oasis the groundwater's eco-environmental indices mainly include soil water content, soil salinity, and the groundwater table depth.

The distribution of vegetation in the arid region is closely related to groundwater table depth (WTD). Different plant species have different capacities to adapt and respond to changes in WTD. To elucidate the relationship between plants and WTD, as well as that between WTD and the ecological balance, plants' hydro-ecological interaction must be determined, particularly in terms of the dependence of their root systems.

Generally, the rhizosphere of shallow-rooted trees is located within a soil layer of $1.0 \mathrm{~m}$. Desert plants have developed shallow horizontal root systems, which can take up topsoil water arising from atmospheric precipitation and dew, as well as deep, vertical root systems, which can extract water from the subsoil in order to meet the plants' physiological requirements (Table 1). The calculation of a water balance shows that the volume of root zone is an important factor affecting the survival rate of seedlings during afforestation. Only when water inputs into the root zone exceed water losses can successful afforestation occur. The extent of the horizontal root system is an important index of a plant's drought resistance under non-irrigated conditions: the larger the horizontal root system and water catchment area, the greater the quantity of water taken up, and the greater the drought resistance.

The main plant species in the Ejin oasis include the desert riparian tree species of Populus euphratica and Elaeagnus angustifolia; xerophytes and halophytes Nitraria tangutorum, Artemisia desertorum, Haloxy- lon ammodendrom, Tamarix chinensis, Kalidium foliatum (Pall.) Moq. and Karelinia caspia (Pall.) Less; hydrophytes Phragmites communis, Calamagrostis epigejos (L.) Roth., Aneurolepidium dasystachys (Trin.) Nevski, Achnatherum splendens, etc. The root systems of these plant species are generally distributed within a soil layer of $3 \mathrm{~m}$, and are mainly concentrated in the topsoil of $1.5 \mathrm{~m}$.

Populus euphratica, a newly introduced species in Ejin, has developed horizontal root systems in a depth ranging from 1 to $3 \mathrm{~m}$. The experiments on cutting poplar roots to promote tillering, undertaken at the Qidaoqiao Poplar Reserve in Ejin, showed that when $0.8 \mathrm{~m}<\mathrm{WTD}<1.8 \mathrm{~m}$, the root systems of poplar trees were mainly distributed in a soil layer of $1.0-1.5 \mathrm{~m}$ (Table 1).

Under non-irrigated conditions the limiting WTD in the poplar forest was $4-5 \mathrm{~m}$, along with a soil moisture volumetric content ( $\theta$, water volume per volume soil) of no less than $1.5 \%$. When WTD varied between 3 and 4 $\mathrm{m}$ and $\theta>1.5 \%$, poplar trees grew normally, but when WTD exceeded $5 \mathrm{~m}$ and $\theta<1.5 \%$, the growth of poplar trees was limited (Table 2). Likewise, when WTD varied between 3 and $4 \mathrm{~m}$ and $\theta>1.0 \%$, drought-resistant Tamarix shrubs grew normally, but when WTD exceeded $5 \mathrm{~m}$ and $\theta<1.0 \%$, their growth was suppressed. When WTD varied between 3 and $4 \mathrm{~m}$, Elaeagnus angustifolia grew normally; however, when WTD exceeded $5 \mathrm{~m}$, they grew poorly (Feng and Cheng, 1998).

Although psammophytes have similar root systems, they require a reasonably shallow WTD, e.g. Calligonum mongolicum shrubs are shallow-rooted, and their optimal WTD is roughly $3 \mathrm{~m}$. If the WTD $>5 \mathrm{~m}$,

Table 1 Variations in plant root system for species common in the lower reaches of the Heihe River Basin

\begin{tabular}{lccc}
\hline \multicolumn{1}{c}{ Plant species } & Root depth $(\mathrm{m})$ & Range of depth at which the root system is densest $(\mathrm{m})$ & Actual groundwater depth $(\mathrm{m})$ \\
\hline Populus euphratica & $2.0-3.0$ & $1.0-2.5$ & 3.0 \\
Elaeagnus angustifolia & $2.0-3.5$ & $1.0-1.5$ & 3.0 \\
Tamarix chinensis & 1.9 & $0.7-1.4$ & 2.7 \\
Artemisia sphaerocephala & 1.2 & $0.2-0.4$ & $2.0-3.0$ \\
Nitraria tangutorum & 3.1 & $1.0-1.8$ & 3.3 \\
Kalidium gracile & 1.8 & $0.8-1.0$ & 3.0 \\
Karelina caspica & 2.7 & $0.5-0.8$ & 2.7 \\
Phragmites communis & 2.4 & $0.3-0.8$ & 2.6 \\
Glycyrrhiza uralensis & $1.5-2.5$ & $1.0-2.0$ & $1.5-2.5$ \\
Apocynum sp. & 1.9 & $0.6-0.8$ & $0.9-2.5$ \\
Calligonum sp. & 2.4 & $0.4-0.8$ & 3.6 \\
Reaumuria soongarica & 2.7 & $0.4-0.8$ & 3.6 \\
Ephedra przewalskii & 1.5 & $0.5-0.8$ & 0.4 \\
\hline
\end{tabular}


No.4 Qi FENG et al:: Using the concept of ecological groundwater level to evaluate shallow groundwater resources in hyperarid...

Table 2 Relationship between predominant plant species and maximum groundwater table depth (WTD)

\begin{tabular}{lcccccc}
\hline \multirow{2}{*}{ Plant species } & \multicolumn{2}{c}{ Economic threshold $(\mathrm{m})$} & \multicolumn{2}{c}{ Suitable threshold $(\mathrm{m})$} & \multicolumn{2}{c}{ Survival threshold (m) } \\
\cline { 2 - 7 } & WTD & Range of variation & WTD & Range of variation & WTD & Range of variation \\
\hline Phragmites communis & $0.0-0.5$ & $<0.5$ & $0.5-1.0$ & $<0.5$ & $1.0-1.5$ & $<0.5$ \\
Populus euphratica & $1.5-2.5$ & $0.5-1.0$ & $2.5-3.5$ & $0.5-1.0$ & $>5.0$ & 0.5 \\
Tamarix chinensis & $1.0-2.0$ & $0.5-1.0$ & $2.0-3.0$ & $0-0.5$ & $>3.5$ & $<0.5$ \\
Haloxylon ammodendron & $1.5-2.5$ & $<0.5$ & $2.5-3.5$ & $0-0.5$ & $>4.0$ & $<0.5$ \\
\hline
\end{tabular}

Table 3 Relationship between the groundwater table depth and the degree of land desertification

\begin{tabular}{|c|c|c|c|c|}
\hline \multirow{3}{*}{ Plant species } & \multicolumn{4}{|c|}{ Degree of land desertification } \\
\hline & Potential & Slight & Moderate & Severe \\
\hline & \multicolumn{4}{|c|}{ Groundwater table depth (m) } \\
\hline Populus euphratica & $<4$ & $4-6$ & $6-10$ & $>10$ \\
\hline Elaeagnus angustifolia & $2-3$ & $4-5$ & $5-6$ & $>6$ \\
\hline Tamarix chinensis & $<5$ & $5-7$ & $7-8$ & $8-10$ \\
\hline Nitraria tangutorum & $<5$ & $5-7$ & $7-8$ & $8-10$ \\
\hline
\end{tabular}

or $\theta<1.0 \%$ they will die off. Tamarix chinensis and Nitraria tangutorum reproduce primarily in a vegetative manner, so they are not very susceptible to sand burial, sandblast or wind erosions. However if WTD $>5 \mathrm{~m}$, they can't survive (Table 2). Haloxylon ammodendron shrubs are sand-fixing pioneer species; however, they may die if water content in sand dunes drops to as low as $1 \%$ (Feng et al., 2001). Thus, overall, when the WTD $>4-5 \mathrm{~m}$, psammophytes can barely survive, while if it drops to below 6-7 $\mathrm{m}$ almost all the plant species will die off.

Generally, the thickness of the dry soil layer reaches a maximum $(0.30-0.50 \mathrm{~m})$ in the spring. When wind velocities reach $4.5 \mathrm{~m} / \mathrm{s}$, sands begin to move and the annual deflation depth can reach $2.2 \mathrm{~mm}$. Strong winds in shifting sandy lands have been reported to result in a deflation depth of as much as $30-50 \mathrm{~mm}$ in some locations. Field investigations in the Ejin oasis indicate that under the same WTD and vegetation type the degree of land desertification can vary (Guo et al., 2009; Table 3). The WTD should be shallower than 4-5 $\mathrm{m}$ so that land desertification can be avoided.

\subsection{Changes in phytoecology and eco-environment}

Small variations in the harsh environmental conditions in the lower reaches of the Heihe River may cause substantial changes in vegetation type, plant species and community structure. Besides water and thermal resources availability, other environmental factors are also important for the growth, development and reproduction of plant communities. The relationship between vegetation and ecosystem has long been an important aspect in plant ecological research, and its study in the lower reaches of the Heihe River will contribute to a better understanding of the environmental evolution trends in the region.

In the lower reaches of the Heihe River, 71 sampling plots (Fig. 1) within 5 typical plant communities were selected on different terrains. Volumetric soil moisture content, soil salinity, precipitation, soil organic matter and $\mathrm{pH}$ were measured at each site, and the plots were then classified and ordered according to these parameters. A regression analysis was performed between vegetation cover and the main environmental factors $(n=71$; Figs. 2,3$)$. The environmental factors of soil $\mathrm{CO}_{3}{ }^{2-}$ or $\mathrm{HCO}_{3}{ }^{-}, \mathrm{pH}$ and organic matter showed little correlation with plant community type.

From the diluvial-alluvial fan edges on both banks of the Heihe River to the feet of the mountains the elevation rises gradually; temperature drops; precipitation increases, and soil water condition improves. The zonal Reaumurica soongorica, Sympegma regelii and

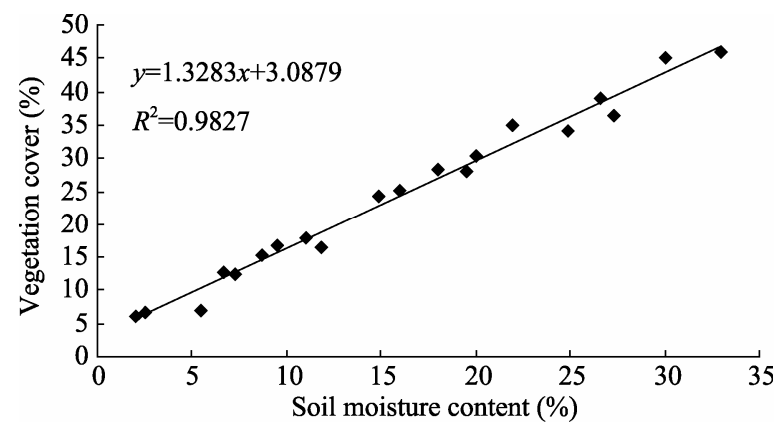

Fig. 2 Relationship between vegetation cover and soil moisture content in the lower reaches of the Heihe River 


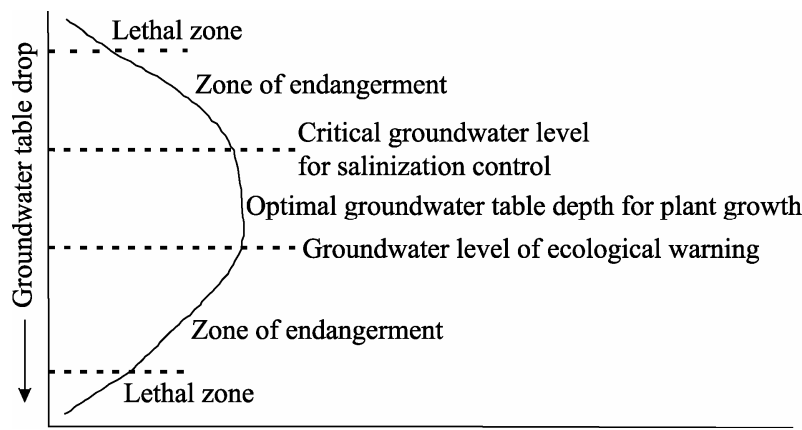

Fig. 3 Relationship between groundwater table depths and plant growth conditions. Different segments of the curve indicate different plant growth conditions.

Nitraria sphaerocarpa, and their associated plants were widely and regularly distributed. Salsola passerina Bunge occurred mainly on the piedmont diluvial fans; Ephedra przewalskii and Calligonum mongolicum on mid-low mountains, hills, interdune depressions and both sides of the river channel; Tamarix chinensis and Lycium ruthenicum Murray on salinized lands with shallow WTD; and Phragmites communis along the river and in swamp lands with shallow WTD.

The vegetation cover varied with soil moisture, generally increasing linearly with increasing soil moisture content in the soil layer of $0-1.0 \mathrm{~m}$ (Fig. 2):

$$
\% V C=3.296+1.396 \theta, \quad(P \leq 0.001) \text {. }
$$

Where $\% V C$ is vegetation cover $\left(\mathrm{m}^{2} / \mathrm{m}^{2}\right)$, and $\theta$ is volumetric soil moisture content (\%) in the $1.0-\mathrm{m}$ topsoil layer. When $\theta$ was about $1 \%$, then $4 \%<\% V C<5 \%$; when $\theta$ was about $5 \%$, then $\% V C$ reached $8 \%$; and when $\theta>20 \%$, then $\% V C>30 \%$. Thus $\theta$ clearly has a significant effect on $\% V C$ in the lower reaches of the Heihe River.

Plant species diversity and soil salinity were closely related. High soil salinity can exacerbate drought severity, and make it more difficult for plants to uptake water. Thus, on salinized lands plant growth and reproduction can be hindered, whereas in soils with low salt content plant species are abundant. The following relationship between soil salinity and plant species diversity was found:

$$
N=6.945 \mathrm{e}^{0.08 / S}, \quad(P \leq 0.01) .
$$

Where $N$ is the number of plant species, $S$ the soil electrical conductivity $(\mathrm{mS} / \mathrm{m}) \times 1000$.

When soil salinity was high $(S=10.0 \mathrm{mS} / \mathrm{m})$ only 3 plant species were present; when soil salt content was low $(S=5.0 \mathrm{mS} / \mathrm{m})$, plant species numbered 6 or 7 , showing a close relation between soil salinity and the number of plant species. Thus, the main environmental factors affecting vegetation cover and species diversity in the lower reaches of the Heihe River were $\theta$ and soil salinity.

\subsection{The groundwater level of ecological warning and its implications}

Based on the relationship between psammophyte growth and WTD, Bushev (1944) put forward the concept of a critical WTD in order to explain soil salinization problems. Likewise, in order to protect vegetation from being threatened by an excessive withdrawal of groundwater, he put forward the concept of a groundwater level threshold of ecological warning, which may vary with different types of vegetation, and serves as a warning against impending ecosystem collapse (Fig. 3, Table 2).

Changes in ecological parameters within an optimal range have little influence on plant growth, whereas beyond this range a small change can significantly affect vegetation (Table 2). The basic points are: (i) the suitable point of WTD, (ii) the groundwater level threshold of ecological warning, when soil water content drops to below field capacity and approaches the plant's wilting point, and (iii) the critical groundwater level for salinity control which represents the groundwater level at which evaporation in the driest season will not cause salt accumulation in the surface soil layer. Consequently, when the WTD is close to the critical groundwater level for salinity control or to the groundwater level of ecological risk, its fluctuations can significantly affect plant growth (Yuan, 1985).

The environmentally critical groundwater level or groundwater level threshold of ecological warning discussed and expressed as $\mathrm{WTD}_{\mathrm{x}}$ in this paper is defined as the WTD at which the largest evapotranspiration and greatest groundwater withdrawal rates occur. A region's $\mathrm{WTD}_{\mathrm{x}}$ can be determined by applying the environmental gradient method ( $\mathrm{Ji}, 1983)$ to accurate observations of plant- water physiological relationships at fixed sites.

According to analyses of the relationship between psammophyte communities and WTD under long-term observations (Tables 1-3), the $\mathrm{WTD}_{\mathrm{x}}$ for the indicator plant species Elaeagnus angustifolia, Tamarix chinen- 
sis and Nitraria tangutorum in the Ejin region is $4 \mathrm{~m}$ deep. The main task in protecting the desert oasis ecosystem is to maintain the WTD below the critical level for salinization control and above $\mathrm{WTD}_{\mathrm{x}}$ (Fig. 3). Thus, land desertification and soil salinization can be avoided, and groundwater can be exploited rationally.

\subsection{Water resources development model and ex- ploitable volume}

The concepts of renewable $\left(Q_{\mathrm{r}}\right)$, ecological $\left(Q_{\mathrm{s}}\right)$ and exploitable $\left(Q_{\mathrm{k}}\right)$ water resources were defined as follows:

$Q_{\mathrm{r}}$ refers to the quantity of water resources rapidly renewed through the extended working of the hydrological cycle. In a region where groundwater resources have been heavily exploited, these resources can be restored to a dynamic balance, through groundwater transferring from adjacent regions. However, if the aquifer is exploited to a great excess and not recharged for a long time, the water resources become non-renewable, as in the Ejin oasis.

$Q_{\text {s }}$ refers to the quantity of water required to maintain sustainable ecosystem development, without consideration for agricultural irrigation or other human demands. Plant water requirements occupy a large proportion of $Q_{\mathrm{s}}$, of which the free water required for plant metabolism and the bound water needed to cope with adverse environmental conditions are commonly termed as physiological water. The remainder includes the quantity of water required to adjust soil temperature, dissolve fertilizers, improve the microclimate, and avoid wind erosion and desertification.

Owing to the physical limitations in the environment, many plant species have a potential to be more productive under ideal conditions. If the regulation of the WTD results in a periodic fluctuation of groundwater levels and causes a synergistic effect between vegetation and other ecological factors, plant growth will be benefited (Kang et al., 2000).

$Q_{\mathrm{k}}$ is the maximum water yield obtainable from a aquifer, where the process of exploiting the shallow groundwater in a hydrologically-linked region (e.g. a small basin, a hydrogeological unit, a water source area or a desert oasis) neither destroys the ecological niches of plant communities nor dries up nearby water bodies (e.g. springs, lakes, fish ponds) when the highest groundwater evaporation rate at $\mathrm{WTD}_{\mathrm{x}}$ occurs.
For a natural ecosystem, renewable water resources are always the sum of ecological water resources and exploitable water resources:

$$
Q_{\mathrm{r}}=Q_{\mathrm{s}}+Q_{\mathrm{k}}
$$

When dynamic observations of WTD are available, Eq. 3 can be rewritten as:

$$
\mu \cdot \Delta h \cdot F=Q_{\mathrm{s}}+Q_{\mathrm{k}} .
$$

Where $\mu$ is the average water supply coefficient, $\Delta h$ variation of groundwater level, and $F$ the area of the region for which water resources are assessed $\left(\mathrm{km}^{2}\right)$.

With existing dynamic WTD observations, the mathematical expression for the quantity of exploitable water resources can be derived from the correlation between the quantity of exploitable water $\left(Q_{\mathrm{k}}\right)$ and the WTD:

$$
\begin{gathered}
Q_{\mathrm{k} i}=\left(\mathrm{WTD}_{\mathrm{x} i}-A_{i}-S_{i}\right) / B_{i}-Q_{\mathrm{l} i},(i=1,2,3, \ldots \ldots \mathrm{n}) . \\
Q_{\mathrm{k}}=\Sigma Q_{\mathrm{k} i}, \quad(i=1,2,3, \ldots \ldots \mathrm{n}) . \\
M=Q_{\mathrm{k}} / F .
\end{gathered}
$$

Where $A_{i}$ and $B_{i}$ are constants of related equations, drawn from long-term observational data. $M$ is the ecological exploitation modulus $\left(10^{4} \mathrm{~m}^{3} /\left(\mathrm{km}^{2} \cdot \mathrm{a}\right)\right), Q_{\mathrm{k} i}$ $\left(10^{8} \mathrm{~m}^{3} / \mathrm{a}\right)$ the quantity of ecologically exploitable water resources in a given subregion classified according to aquifer attitude type $(\mathrm{m})$ and vegetation cover, $Q_{\mathrm{k}}$ $\left(10^{8} \mathrm{~m}^{3} / \mathrm{a}\right)$ the total ecologically exploitable water resources for the entire region being assessed, $\mathrm{Q}_{1 i}\left(10^{8}\right.$ $\mathrm{m}^{3} / \mathrm{a}$, about $2.43 \times 10^{8} \mathrm{~m}^{3} / \mathrm{a}$ ) the groundwater runoff necessary to avoid the deterioration of the surrounding aquatic environment (Feng et al., 2008), $S_{i}$ (m) the annual range in $\mathrm{WTD}, \mathrm{WTD}_{\mathrm{x} i}(\mathrm{~m})$ the environmentally critical groundwater level in a given subregion, and $i$ the subregion number.

The quantity of ecologically exploitable water resources in the Ejin region was calculated according to Eqs. 3-6.

Roughly $9.4 \%$ and $90.6 \%$ of the Ejin region's groundwater originates from atmospheric precipitation and subsurface lateral runoff, respectively (Ma and Qian, 1997; Ma and Gao, 1998). Since groundwater in the Ejin region mainly comes from inflow arising in the upper to middle reaches of the Heihe River, the upper reaches-originating water inputs involved in maintaining sustainable downstream ecosystem development $\left(Q_{1}\right)$ is calculated according to the relationship between upstream incoming flow and the deepest annual WTD $\left(\mathrm{WTD}_{\max }\right)$ in the low-lying region. 
Figure 4 presents the result of regional WTD observations since 1957. Accordingly, a linear correlation between WTD and inflow at Zhengyixia station was established for a period of nearly 40 years (19571995):

$$
\mathrm{WTD}=4.3681-0.3713 \times 10^{-8} \mathrm{Q}_{1}
$$

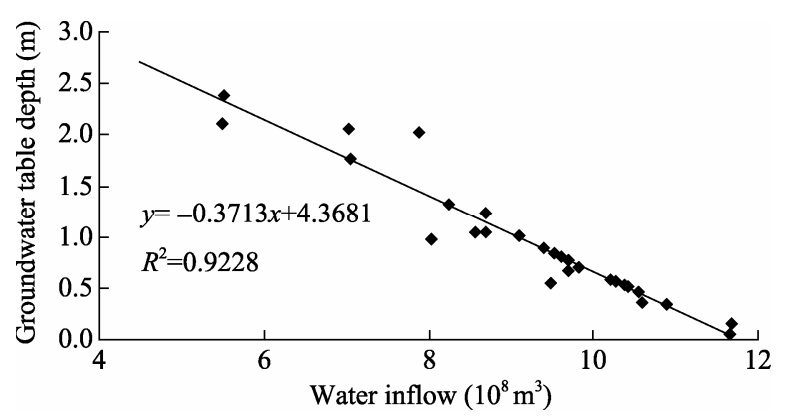

Fig. 4 Relationship of groundwater table depth and water inflow in the lower reaches of the Heihe River

According to a physical interpretation of Eq. 7 and local ecological limiting factors, the study defined the annual maximum and minimum water supply volumes for the different regions. Natural environments in the desert regions are harsh, and changes in water-related factors can cause chain reactions. Local water consumption for the natural ecosystem, the relationship between WTD and psammophyte growth regime, and the quality of groundwater could determine the need for replenishment of groundwater. The greatest problem in the Ejin region is to determine the appropriate WTD range, in an ecological perspective. According to field observations, when near-bank (1-2 km) WTD in the Ejin oasis fell to below $3 \mathrm{~m}$, the WTD in the more distal zone $(2-4 \mathrm{~km})$ dropped to below $4 \mathrm{~m}$. Therefore, the deepest designed WTD for the near-bank zone should be $3 \mathrm{~m}$, while that for environmental restoration should be $2 \mathrm{~m}$. Since the lowest WTD coincides with riparian plants' critical water demand, the relationship between WTD changes in the lower reaches of the Heihe River and the incoming flow from the middle (Fig. 4) can be described as:

$$
\mathrm{WTD}_{\max }=4.368-0.37 \times 10^{-8} Q_{\mathrm{k}}{ }^{\max } \text {. }
$$

Where $\mathrm{WTD}_{\max }(\mathrm{m})$ is the maximum WTD during the dry period, and $Q_{\mathrm{k}}{ }^{\max }\left(10^{8} \mathrm{~m}^{3}\right)$ is the maximum water requirement at $\mathrm{WTD}_{\max }$.

As calculated from Eqs. 3-8, for a maximum WTD of $3 \mathrm{~m}$ (allowing the region's vegetation to be restored), 2.5 or $2.0 \mathrm{~m}$, the minimum water supplies required would be $0.39 \times 10^{8}, 0.53 \times 10^{8}, 0.68 \times 10^{8} \mathrm{~m}^{3} / \mathrm{a}$, respectively. According to the Water Distribution Scheme of the Main Stream of the Heihe River promulgated by the Chinese Ministry of Water Resources, when the mean discharges at the mountain valley mouth are $1.70 \times 10^{8}, 1.58 \times 10^{8}, 1.42 \times 10^{8}$ and $1.29 \times 10^{8}$ $\mathrm{m}^{3} / \mathrm{a}$, respectively, the draw-off discharges at Zhengyixia station are $1.09 \times 10^{8}, 0.95 \times 10^{8}, 0.76 \times 10^{8}$, and $0.63 \times 10^{8} \mathrm{~m}^{3} / \mathrm{a}$, respectively. When the inflow reaches $1.10 \times 10^{8} \mathrm{~m}^{3} / \mathrm{a}$, the WTD in the oasis ranges between 2 and $3 \mathrm{~m}$, whereas, if the inflow is limited to $0.63 \times 10^{8}$ $\mathrm{m}^{3} / \mathrm{a}$, the WTD will vary between 3 and $4 \mathrm{~m}$, i.e. WTD $>$ WTD $_{\mathrm{x}}$.

\subsection{Exploitable water resource amount}

According to the general law of inflow and groundwater recharge, if the deepest annual dynamical WTD in a shallow groundwater region $\left(\mathrm{WTD}_{\max }\right)$ and the ecological warning groundwater depth $\left(\mathrm{WTD}_{\mathrm{x}}\right)$ are viewed as sequential parameters which can serve in the study of evolutional trends in the quantity of exploitable water resources or of water requirements, i.e. $Q_{\mathrm{x}}$, then we can accurately estimate the ecological capacity of the aquatic regime. The exploitation of water resources in the Ejin oasis can be divided into three interchangeable types: recoverable, coordinated and predatory. This provides a basis for ecological regionalization and the study of the influences of midstream water diversion on downstream WTD and ecosystems.

Recoverable exploitation occurs when ((WTD ${ }^{-}$ $\left.\left.\mathrm{WTD}_{\max }\right) / \mathrm{WTD}_{\mathrm{x}}\right)>0$ and $Q_{\Delta \mathrm{x}}\left(Q_{\Delta \mathrm{x}}\right.$ is the variation value of $Q_{\mathrm{x}}$ ) increases (Fig. 5a). In such a case, the amount of ecological water supply exceeds the ecological water consumption; the WTD gradually raises; the volume of groundwater resources increases; ecosystems tend to be restored; and water availability within the environment is improved. This situation indicates that local water resources are not a limiting factor to economic development and there is a certain potential to develop groundwater resources.

Coordinated exploitation occurs when ((WTD ${ }^{-}$ $\left.\left.\mathrm{WTD}_{\max }\right) / \mathrm{WTD}_{\mathrm{x}}\right)=0$ and $Q_{\Delta \mathrm{x}}$ approaches zero (Fig. $5 \mathrm{~b}$ ). Under such conditions, the water supply and ecosystem 

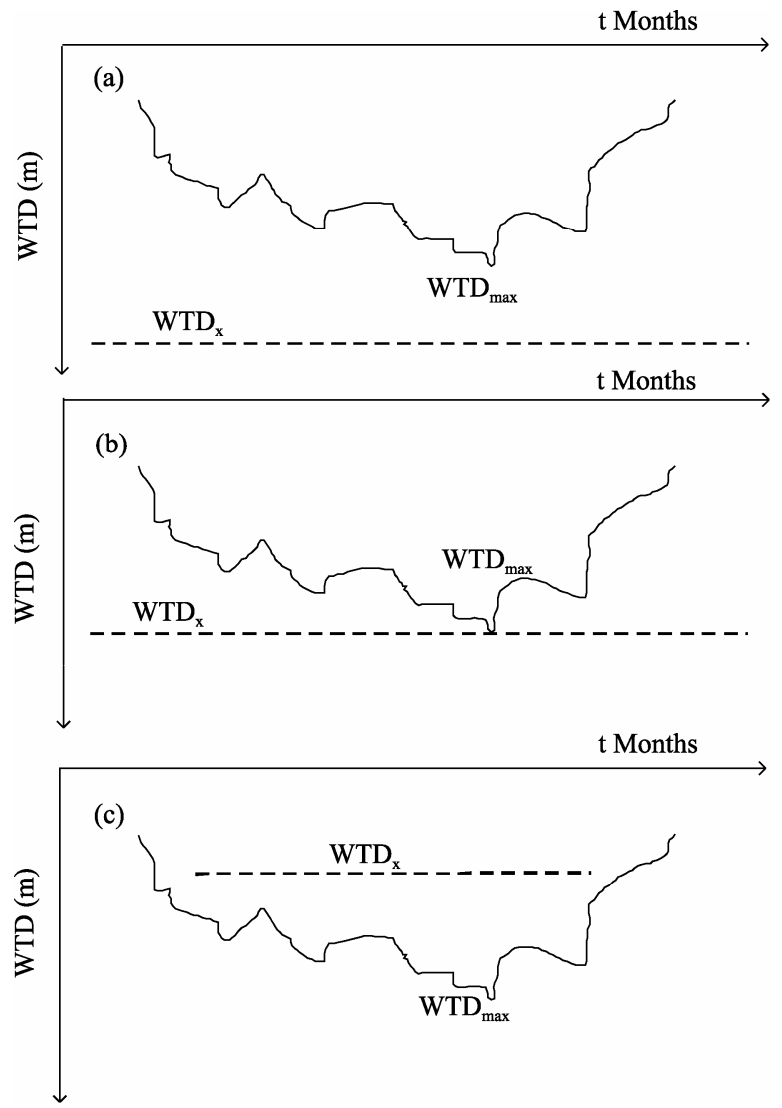

Fig. 5 Relationship between the groundwater table depth variation and maximum groundwater table depth; $a, W_{T} D_{x}>W^{2} D_{\text {max }} ; b$, $\mathrm{WTD}_{\mathrm{x}}=\mathrm{WTD}_{\max } ; \mathrm{c}, \mathrm{WTD}_{\mathrm{x}}<\mathrm{WTD}_{\max }$.

water requirements are balanced; the ecological capacity of the aquatic environment reaches its limit; WTD is stable; and the ecological regime and production are in a coordinated state. In such a case, unexploited groundwater is in a relatively balanced state. However, efforts should be made to avoid excessive withdrawals of groundwater for economic development.

Predatory exploitation occurs when ((WTD ${ }^{-}$ $\left.\left.\mathrm{WTD}_{\max }\right) / \mathrm{WTD}_{\mathrm{x}}\right)<0$ but $Q_{\Delta \mathrm{x}}$ decreases (Fig. 5c). In such a case, ground and surface water cannot meet ecosystem water requirements and the ecological regime of the aquatic environment is destroyed (Fig. 6). This result indicates that the region is facing a water-shortage problem and ecosystems are worsening. Measures should be adopted to increase surface water, recharge groundwater, close pumping wells to decrease groundwater extraction, and decrease the area of cultivated lands to protect the oasis.

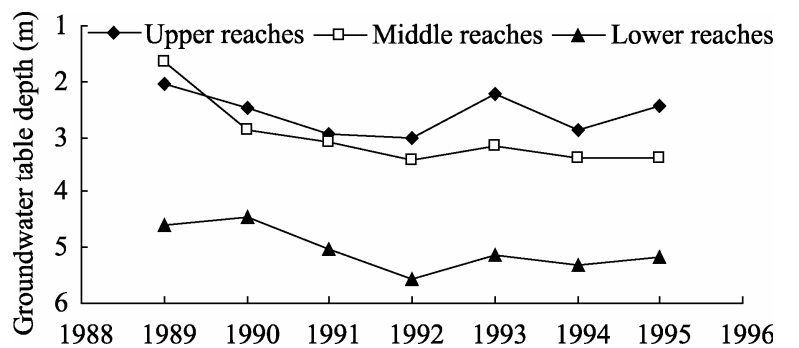

Fig. 6 Annual mean groundwater table depth in the lower reaches of the Heihe River (1989-1995). Upper reaches, location at Laoximiao in Fig. 1; Middle reaches, location at No. 2 sampling site in Fig. 1; Lower reaches, No. 1 sampling site in Fig. 1.

\section{Conclusions}

As water resources are among the primary factors regulating ecosystem productivity in arid regions, excessive exploitation of water resources would lead to ecosystem degradation. Therefore, an environmentally critical WTD indicator should be developed in a manner which considers both ecological and hydrogeological issues. An arid inland river basin management model based on the concept of an ecologically sustainable portion of exploitable water resources should be developed and used to address regional development issues and associated exploitation of shallow groundwater resources from the desert oasis. By using precise WTD data recorded at several observation points and the ecological sequence method (i.e. environment gradient method) we can estimate the water availability.

According to the relationship between water supply from the middle reaches of the Heihe River and groundwater level variations in the Ejin oasis of nearly 40 years, the minimum and maximum water supply volumes are $5.3 \times 10^{8} \mathrm{~m}^{3} / \mathrm{a}$ and $3.85 \times 10^{8} \mathrm{~m}^{3} / \mathrm{a}$ for the Ejin delta, respectively. The water supply volume can ensure that groundwater levels of the oasis remain between $2.0-4.0 \mathrm{~m}$, which is an optimal range for plant growth. The model is applicable for the analysis of groundwater level changes in the assessment of regional water resources under the situation of limited hydrogeological information or unavailable data. This study showed that the developmental types of water resources in arid regions could be divided into recoverable, coordinated and predatory. 
Strategies to protect and restore ecosystems in the Heihe River Basin include the return of grazing lands to wetlands, the control of per capita water consumption, adjustment of cultivation practices, greater water-conserving inputs, reduction of irrigated croplands, and increase in irrigated grassland areas. In the distribution and utilization of water resources, we should not only consider economic benefits, but also take into account environmental water requirements, using field measures to assess when to replace leaky canals, manage water-soil salinity, standardize the management of

\section{References}

Al Aasm I S. 1990. Stable isotope analysis of multiple carbonate samples using selective acid extraction. Chemical Geology, 80: $119-125$.

Asbjornsen H, Mora G, Helmers M J. 2007. Variation in water uptake dynamics among contrasting agricultural and native plant communities in the Midwestern US. Agriculture, Ecosystems and Environment, 121(4): 343-356.

Bouyoucos G H. 1951. A recalibration of the hydrometer method for making mechanical analysis of soils. Agronomy Journal, 43: 434-438.

Bresler E, Kemper W D, Hanks R J. 1969. Infiltration, redistribution, and subsequent evaporation of water from soil as affected by wetting rate and hysteresis. Soil Science Society of America Journal, 33: 832-840

Brewer R. 1964. Fabric and Mineral Analysis of Soils. New York: Wiley, 53-55.

Briggs L J, Shantz H L. 1921. The relative wilting coefficient for different plants. Botanical Gazette, 53: 229-245.

Bushev M. 1994. Synergetics: Chaos, Order, Self-organization. Singapore: World Scientific, 56-59.

Cao S X, Feng Q. 2012. Asian medicine: exploitation of plant. Science, 335: 1168-1169.

Charney J, Stone P H, Quirk W J. 1975. Drought in the Sahara: a biogeophysical feedback mechanism. Science, 187: 434-435.

Chen Z Y, Nie Z L, Zhang G H, et al. 2006. Environmental isotopic study on the recharge and residence time of groundwater in the Heihe River Basin, northwestern China. Hydrogeology Journal, 14: 1635-1651.

Cheng L H, Qu Y G. 1992. Rational Development and Use of Water and Land Resources in Hexi Region. Beijing: Science Press, 45-49.

Corwin D L, Rhoades J D. 1982. An improved technique for determining soil electrical conductivity depth relations from above ground electromagnetic measurements. Soil Science Society of America Journal, 46: $517-520$.

Dalton F N, Herklerath W N, Rawlins D S, et al. 1984. Time domain reflectrometry: simultaneous measurement of the soil water content surface and groundwater, and optimize the allocation of water to diversions, storage and pumped irrigation.

\section{Acknowledgements}

This work was funded by the National Natural Science Foundation of China (91025002; 30970492), the Fundamental Research Funds for the Central Universities (GK201101002), the Key Project of the Chinese Academy of Sciences (KZZDEW-04-05), and the National Key Technology R \& D Program (2012BAC08B05). The authors would like to express their deep gratitude to the anonymous reviewers for their valuable suggestions that greatly improved the manuscript.

and electrical conductivity with a single probe. Science, 224: 989-990.

Dong Y X, Liu Y Z, Liu Y H. 1995. Study on Several Problems of Desertification. Xi'an: Map Publishing House, 78-89.

Drimmine R J, Heemskerk A R, Paiion M E. $1992 .{ }^{13} \mathrm{C}$ and ${ }^{18} \mathrm{O}$ in Carbonates. In: Environmental Isotope Laboratory. Technical Procedure 11.0, Rev 01: University of Waterloo, 10-12.

Enrico F L, Laura G V, Woldu Z H. 2002. Evaluation of environmental degradation in Northern Ethiopia using GIS to integrate vegetation, geomorphologic, erosion and socio-economic factors. Agriculture, Ecosystems and Environment, 91: 313-325.

Feng Q, Cheng G D. 1998. Relation between vegetation growth and ecological groundwater table in desert oasis. Journal of Desert Research (Suppl.), 18(1): 34-41.

Feng Q. 1999. Sustainable utilization of water resources in Gansu province. Chinese Journal of Arid Land Research, 11: 293-299.

Feng Q, Cheng G D, Endo K H. 2001. Water content variations and respective ecosystems of sandy land in China. Environmental Geology, 40(9): 1075-1083.

Feng Q, Cheng G D, Endo K H. 2002. Towards sustainable development of the environmentally degraded river Heihe Basin, China. Hydrological Science Journal, 46(5): 647-658.

Feng Q, Liu W. 2003. Water resources management and rehabilitation in China. Journal of Experimental Botany, 54: 23-28.

Feng Q, Liu W, Su Y H, et al. 2004. Distribution and evolution of water chemistry in Heihe River basin. Environmental Geology, 45: 947-956.

Feng Q, Liu W, Xi H Y. 2009. Relationship between soil physiochemistry and land degradation in the lower Heihe River basin of northwestern China. Frontiers of Earth Science in China, 3(4): 490-499.

Guo Q L, Feng Q, Li J L. 2009. Environmental changes after ecological water conveyance in the lower reaches of Heihe River, Northwest China. Environmental Geology, 58: 1387-1396.

Gao Q Z, Li F X. 1991. Rational Use of Water Resources in the Heihe River Basin. Lanzhou: Gansu Scientific and Technological Press, 134-154.

Hillel D.1974. Methods of Laboratory and Field Investigation of 
Physical Properties of Soils. In: Transepts of the $10^{\text {th }}$ International Soil Science Congress, vol 1, Moscow, 302-308.

Hillel D. 1982. Negev: Land, Water and Life in a Desert Environment. New York: Praeger, 58-89.

Holmes J W. 1956. Calibration and field use of the neutron scattering method of measuring soil water content. Australian Journal of Applied Science, 7: 45-58.

Ji C M. 1983. Several problems on water resources survey methods in America and Japan. Hydrogeology and Engineering Geology, 4.

Jin X M, Hu G C, Li W M. 2008. Hysteresis effect of runoff of the Heihe River on vegetation cover in the Ejin oasis in Northwestern China. Earth Science Frontiers, 15: 198-203.

Kang S Z, Shi P, Pan Y. 2000. Soil water distribution, uniformity and water-use efficiency under alternate furrow irrigation in arid areas. Irrigation Science, 19(4): 181-190.

Liu X H, Zhang C X. 2002. Status and protection of vegetation in Ejin oasis. Forestry Survey and Design of Inner Mongolia, 25(4): 34-35.

Ma J Z, Qian J. 1997. The Optimal Exploitation and Utilization of Water Resources in Heihe River Basin. Journal of Lanzhou University (Nature Sciences), 33(2): 92-97 (2).

Ma J Z, Gao Q Z. 1998. A DDP model of optimal multicrop allocation of agricultural irrigation water in arid NW China. Journal of Lanzhou University (Nature Sciences), 34(3): 145-150.

Rhoades J D. 1976. Measuring, mapping, and monitoring field salinity and water table depths with soil resistance measurements. FAO Soils Bulletin, 31:159-186.

Rhoades J D. 1978. Monitoring soil salinity: a review of methods. In: Everett L G, Schmidt K D. Establishment of Water Quality Monitoring Programs. American Water Research Association, 150-165.

Rhoades J D. 1980. Predicting bulk soil electrical conductivity versus saturation paste electrical conductivity calibrations from soil properties. Soil Science Society of America Journal, 45: 42-44.

Rhoades J D, Corwin D L. 1980. Determining soil electrical conductivity-depth relations using an inductive electromagnetic soil conductivity meter. Soil Science Society of America Journal, 45: 255-260

Rhoades J D. 1984. Principles and methods of monitoring soil salinity. In: Shainberg I, Shalhevet J. Soil salinity under Irrigation-processes and Management. Berlin Heidelberg New York: Springer, 130-142.

Romanek C S, Grossman E L, More J W. 1996. Carbon isotopic fractionation in synthetic aragonite and calcite: effects of temperature and precipitation rate. Geochim Cosmochim Acta, 56: 419-430.

Second Geology Investigation Team of Northwest China. 1975, 1990, 1995, 2008. Groundwater Resources in Northwest China. Beijing:
Geology Press.

Shu J M, Wang J J, Zheng B H. 1998. Eco-environment deterioration state and its rehabilitation suggestions. Study of Environment Science, 11(4): 55-61.

Si J H, Feng Q, Xi H Y, et al. 2008. Ejin desert oasis: a fragile "ecological screen" in inland region of Northwest China. The $2^{\text {nd }} I n-$ ternational Conference on Bioinformatics and Biomedical Engineering (iCBBE 2008). Shanghai: IEEE Press.

Soil Conservation Service. 1967. Soil survey laboratory methods and procedures for collecting soil samples. Washington: Soil Survey Investigation Report no 1, USDA, 34-78.

Tarutani T, Clayton R N, Mayeda T K. 1969. The effect of polymorphism and magnesium substitution on oxygen isotope fractionation between calcium carbonate and water. Geochim Cosmochim Acta, 33: 987-996.

Umar A, Umar R A, Hmad M S. 2001. Hydrogeological and hydrochemical framework of regional aquifer system in KaliGanga subbasin, India. Environmental Geology, 40(4-5): 602-611.

Van Stempvoort D R, Krouse H R. 1994. Controls of $\delta^{18} \mathrm{O}$ in sulfate: review of experimental data and application to specific environments. In: Alpers C N, Blowes D W. Environmental Geochemistry of Sulfide Oxidation: American Chemical Society Symposium Series 550, 446-480.

Wang X Z, Wang L X, Xie B Y. 2003. Eco-environment construction issues in the Heihe River Basin. Journal of Water and Soil Conservation, 17(1): 33-36.

Wang Y B, Feng Q, Si J H, et al. 2011. The changes of vegetation cover in Ejin Oasis based on water resources redistribution in Heihe River. Environmental Earth Sciences, 64: 1965-1973.

Wu X, Shi S, Li Z H. 2002. The study of the aquifer system in the lower reaches of Heihe River Ejina Basin, Northwest China (II). Hydrology and Engineering Geology, 2:30-33.

Wu Y, Wen X, Zang Y. 2004. Analysis of the exchange of groundwater and river water by using Radon-222 in the middle Heihe Basin of northwestern China. Environmental Geology, 45: 647-653.

Xi H Y, Feng Q, Si J H. 2010. Impacts of river recharge on groundwater level and hydrochemistry in the lower reaches of Heihe River Watershed, northwestern China. Hydrogeology Journal, 18: 791-801.

Yuan S L. 1985. Dynamical characteristics of groundwater at Eastern desert margin in the Heihe River basin, Groundwater, 4.

Zhu G F, Su Y H, Hang C L. 2010. Hydrogeochemical processes in the groundwater environment of Heihe River Basin, Northwest China. Environmental Earth Sciences, 60(1): 139-153.

Zhu Z D, Wang T. 1993. Trends of desertification and its rehabilitation in China. Desertification Control Bulletin, 22: 27-30. 